Article

\title{
Experimental Study on the Heat Release Operational Characteristics of a Soil Coupled Ground Heat Exchanger with Assisted Cooling Tower
}

\author{
Weibo Yang ${ }^{1,2,3,4, *}$, Binbin Yang ${ }^{1}$ and Rui $\mathrm{Xu}^{1}$ \\ 1 School of Hydraulic, Energy and Power Engineering, Yangzhou University, Yangzhou 225127, China; \\ by9264246@163.com (B.Y.); $18205278319 @ 163 . c o m$ (R.X.) \\ 2 State Key Laboratory for Geo Mechanics and Deep Underground Engineering, China University of Mining \\ \& Technology, Xuzhou 221008, China \\ 3 Key Laboratory of Thermo-Fluid Science and Engineering (Xi'an Jiaotong University), Ministry of Education, \\ Xi'an 710049, China \\ 4 Key Laboratory of Efficient \& Clean Energy Utilization, the Education Department of Hunan Province, \\ Changsha 410114, China \\ * Correspondence: yangwb2004@163.com; Tel.: +86-514-8797-1315
}

Received: 3 December 2017; Accepted: 26 December 2017; Published: 1 January 2018

\section{Check for updates}

\begin{abstract}
Hybrid ground source heat pump systems (HGSHPS) with assisted cooling towers is one of the most efficient cooling and heating technologies for buildings with cooling-dominated loads. For the system, the coupled heat release mode between the ground heat exchanger (GHE) and cooling tower is vital for underground soil temperature recovery characteristics and system operation performance. In order to obtain the heat release operation characteristics with different coupled modes of the GHE and cooling tower, a set of multi-functional heat release experimental systems of soil coupled GHE with assisted cooling tower was constructed. The experimental investigations on the system heat release operation characteristics operated in the separate GHE heat release mode, combination heat release mode and day and night alternate heat release mode were undertaken based on the experimental system. The results show that for the separate GHE heat release mode, the heat release rate of GHE rises rapidly during the first two hours of operation, then, gradually tends to be steady, and the soil excess temperatures at various depths gradually rise with time. For the combination heat release mode with continuous operation of cooling tower, in view of reducing soil heat accumulation and accelerating soil temperature recovery, it is more conducive to the heat release by opening the cooling tower on sunny days. For the combination heat release mode with intermittent operation of cooling tower, when the total time ratio of cooling tower running to stop is constant, the intermittent time is longer, the better the effect of soil temperature recovery. Additionally, the soil temperature recovery rate can be improved greatly by the release heat operation of cooling tower during night, and the longer the cooling tower runs, the closer the soil temperature is to the initial temperature.
\end{abstract}

Keywords: hybrid-ground source heat pump system; cooling tower; combination heat release mode; day and night alternate heat release mode

\section{Introduction}

Energy shortage and environmental pollution have given rise to the utilization of clean and renewable energy sources. Among them, ground source heat pump (GSHP) is considered to be one of the most promising renewable utilization technologies to supply heating and cooling for buildings [1]. 
It uses the relatively constant temperature of the earth, which is higher in winter and lower in summer than the ambient air temperature [2]. As a consequence, GSHP system can obtain higher and more stable operating efficiency than the traditional air source heat pump. Therefore, GSHP systems have been widely used for heating and cooling in various types of buildings [3].

However, the advantages of GSHP could be weakened in cooling-dominated districts where the building annual total cooling load is greater than total heating load and more thermal energy is released into the ground than extracted from it. This will cause the increase of ground temperature year after year, and may ultimately degrade the performance of GSHP [4]. A feasible means is to utilize a hybrid ground source heat pump system (HGSHPS) that couples a traditional GSHP system with a supplemental heat rejection equipment, usually a cooling tower. The HGSHPS with a supplemental cooling tower can dramatically reduce the first cost and balance the annual ground loads, and thus has been shown to significantly improve the economics of the system [5].

For the HGSHPS with assisted cooling tower, the operational strategies of the cooling tower are vital for the system performance, because the different operational strategies mean different couple heat release modes between the GHE and cooling tower, and will result in different soil temperature variations and resume characteristics. This, will in turn, affect the performance of GSHP. So, it is essential to find out the heat release operation characteristics of HGSHPS with different couple modes of GHE and cooling tower for ensuring efficient operation of the system [6,7].

Currently, there is a lot of work that has been carried out to investigate the operation performance of HGSHPS by numerical simulations, and many solutions such as HGSHPS with supplemental cooling tower have been presented to balance ground loads on an annual basis. Balasubramanian et al. [8] investigated numerically the feasibility of incorporating a compact closed wet cooling tower to a GSHP for a residential house with $195 \mathrm{~m}^{2}$. It is concluded that adding a closed wet cooling tower can reduce first costs due to shorter length needed for GHE, improving the heat pump efficiency and prolonging the lifetime of the borehole field by reducing the ground temperature rise. Sayyadi and Nejatolahi [9] put forward a new means of optimization for cooling tower assisted GSHP from thermodynamics and thermoeconomic aspects based on the total revenue requirement method. It can be seen that thermodynamic optimization is economical when the operating time is long in the cooling season and the change of water price has no significant effect on the total costs. Man et al. [10] compared the influences of four different control strategies on the performances of two different HGSHPS applied in cooling-dominated buildings based on a practical hourly simulation model. The results show that starting the cooling tower when the inlet water temperature of the heat pump is $3{ }^{\circ} \mathrm{C}$ higher than the air wet bulb temperature in cooling circulation is the best control strategy. Man et al. [11] designed HGCHPS and GSHP systems for a private residential building located in Hong Kong and the comparison of the first and operation investment was considered. It is concluded that selecting the proper HGSHPS can markedly decrease the cost of air-conditioning in hot-weather districts. Cui et al. [12] proposed the fixed load ratio control strategy in the parallel HGSHPS and further investigated the control strategies for different HGSHPS configurations based on the optimal auxiliary cooling ratio. The simulation results show that for the series HGSHPS, the optimum temperature that cooling water enters the heat pump to activate and close the cooling tower are $30^{\circ} \mathrm{C}$ and $28{ }^{\circ} \mathrm{C}$, respectively. Chiasson et al. [13] presented a study on the optimization which is defined as balancing the annual thermal loads in HGSHPS systems. It is found that the total ground loop length is reduced to $80.5 \%$ after adding the cooling tower under the premise of maintaining the soil heat balance. Gang et al. [14] put up with a new control strategy for HGSHPS which was to compare the water temperatures at the exit of GHE and cooling tower directly. It is shown that the new control method can both make the best of the heat exchange advantages and save more energy. Singh and Das [15] presented an optimization model which was set up for a mechanical draft cooling tower installed in heating ventilation and air conditioning (HVAC) and HGSHPS applications. It is found that this optimization method can realize the smallest exergy destruction and meet the imposed heat load. Yang et al. [16] put forward an intermittent operation strategy for the HGSHPS with double cooling 
towers to solve the problem of soil heat accumulation. It can be seen that the HGSHPS can reduce soil heat accumulation under intermittent operating conditions and the energy saving is evident especially in the heat pump which is used for continuous, long-term operations. Zhang et al. [17] studied the performance of HGSHPS under three common control strategies. It is concluded that the optimal strategy is taking the outlet fluid temperature of the buried pipe as the primary parameter, while the difference between the exit temperature of the heat pump and the local wet bulb temperature is taken as the secondary control parameter. Sagiaet al. [18] investigated three new control strategies which were defined by calculating new set points for the HGSHPS. The results indicate that the system can achieve better operation performance and reduce the power consumption under the new control strategies. Lubis et al. [19] performed thermodynamic analysis of HGSHPS assisted by a cooling tower by using energy and exergy analyses. It can be concluded that the coefficient of performance (COP) and exergy efficiencies of the hybrid GSHP systems are higher than typical air source heat pump systems. Lee et al. [20] focused on a test of transient performance characteristics of the HGSHPS with cooling tower in the cooling mode. It is found that the average COP of HGSHPS is higher than that of GSHP under the optimal condition and that the fluid flow rate through the plate heat exchanger and the set-point temperature of the HGSHPS are $8 \mathrm{~kg} / \mathrm{min}$ and $30^{\circ} \mathrm{C}$, respectively. Zhou et al. [21] put forward a plan of operating the cooling tower during the transitional seasons in order to reduce the heat accumulation in the HGSHPS. It is shown that starting up the cooling tower when the temperature is within $8-12{ }^{\circ} \mathrm{C}$ could effectively lower the ground temperature rise and reduce energy consumption. Wei et al. [22] come up with a novel hybrid optimization algorithm to find the optimized set-points of the power cost. It is concluded that the optimized system could greatly decrease energy consumption in the cooling mode. Gang and Wang [23] predicted the temperature of the water exiting the GHE to control the HGSHPS based on artificial neural network model. The results show that the artificial neural network (ANN) model could ensure that the absolute temperature error is within $0.2{ }^{\circ} \mathrm{C}$. Sagia et al. [24] calculated the packing height of cooling tower used in a HGSHPS under different operating conditions by creating a MATLAB code. The results show that the cooling tower could achieve the best effect by using vertical plastic honeycomb packing. Wang et al. [25] studied two common control strategies of HGSHPS and the optimal control operating points were achieved. The simulation results indicate that controlling the exit fluid temperature (ExFT) of the heat pump units is better than controlling the entering fluid temperature (EFT) of the heat pump units. Wang et al. [26] presented a study with the purpose of comparing multiple control strategies used in the HGSHPS based on eQUEST 3.7. The test data show that the HGSHPS could meet the needs of users and maintain soil heat balance under the appropriate control strategies. Hu et al. [27] proposed a multivariable extremum seeking control strategy for HGSHPS. The calculated results indicate that the method could minimize the total power consumption of the heat pump system and the extremum seeking control strategy has significant potential to realize great energy efficiency. Balasubramanian et al. [28] simulated the residential HGSHPS with compact cooling tower to reduce the high initial cost. Conclusions drawn are that the lifetime of the ground loop is increased due to the lower water temperature and the operating costs is decreased because of the improved efficiency. Han et al. [29] put forward a control strategy of the HGCHPS based on wet bulb temperature and introduced a method of confirming the control parameters. It can be seen that the system had better operating performance and ensured the soil thermal balance under the control strategy. Nguyen et al. [30] performed five sensitivity analyses of the HGSHPS to get better acquainted with its optimization factors. It is concluded that operating duration, operating costs, inflation rates, weather, and control strategies play significant roles in the cost and design of HGSHPS.

Also, some experimental studies have been conducted to investigate the performance of HGSGPS. Hackel et al. [31] monitored the annual operation performance of HGSHPS installed in three buildings, among which, two buildings are dominated by cooling and one dominated by heating. The test data show that HGSHPS could both reduce the first costs and benefit the environment. Fan et al. [32] presented the theoretical design for a practical HGSHPS and experimentally studied various factors 
and operating strategies for the HGSHPS to address the soil heat balance problem. It is shown that operating the cooling tower during the transition season can control the increase of the soil temperature and solve the decrease in system performance when the operating time is long. Park et al. [33] carried out an experimental investigation of a HGSHPS which combines a ground flow loop and a heat rejecter loop in parallel. The test data show that the COP of HGSHPS is higher than that of conventional GSHP and the heat release rate of the buried pipe is lower than that of GSHP. Wang et al. [34] investigated the operation control strategies of GSHP with cooling tower. The experimental results show that the performance characteristics of the unit and the operating characteristics of the cooling tower play significant roles in the average COP and power consumption of the HGSHPS. Park et al. [35] compared the performance between the GSHP and HGSHPS with series and parallel configurations. It is concluded that the performance factors of the HGSHPS are larger than that of the GSHP in the summer. Guo et al. [36] reviewed and discussed different HGCHPS applied in China and conducted an experimental study on the operation control strategy of HGCHPS. It is found that the maximum system COP could be obtained by controlling the cooling tower according to the temperature difference between the inlet fluid temperature of the heat pump and the ambient wet bulb temperature.

Based on above literature reviews on the researches of HGSHPS, it can be seen that the present studies mostly concentrate on the performance investigations of HGSHPS by numerical and experimental methods. The research contents include hybrid system optimization, control strategies and performance improvement by adding the assisted cooling tower. The HGSHPS is a type of complicated system with the ground source and assisted cooling tower, and thus its operation performance is not only related to ground heat source characteristics and cooling efficiency of cooling tower, but also depends on their coupling forms. Especially, heat release operation characteristics with different coupling forms of GHE and cooling tower were still less understood. In this work, a set of multi-functional heat release experimental systems of the soil coupled GHE with assisted cooling tower was built. The experimental investigations on the heat release operation characteristics of soil coupled GHE with assisted cooling tower were carried out. The heat release rate and soil temperature recovery characteristics operated in the separate GHE heat release mode, combination heat release mode and day and night alternate heat release mode are obtained and evaluated, respectively.

\section{Experimental System Description}

\subsection{Components of the System}

A set of multi-functional heat release experimental system of the soil coupled GHE with assisted cooling tower was built in Yangzhou University [37]. As shown in Figure 1, the experimental device include an insulated water tank with heaters, GHEs, cooling tower, plate heat exchanger, water pumps, adjust valves, flow meters, and data logger system. Here, the insulated water tank with heaters is used to simulate the cooling load from the condenser of the heat pump unit. Water is heated by the electric heaters and the heat is released into the soil by the GHEs or outdoor air by operating the cooling tower or both by the GHEs and cooling tower through the couple of plate heat exchangers. Also, the heat stored in the soil during the daytime can be rejected to outdoor air through starting the cooling tower during the night so as to accelerate the soil temperature recovery. The switch between different heat release operation modes can be achieved through adjusting the valves shown in Figure 1.

Insulated water tank: Here, in order to easily control the inlet water temperature of GHEs, an insulated water tank with the size of $0.8 \mathrm{~m} \times 0.8 \mathrm{~m} \times 1.2 \mathrm{~m}$ was used to simulate the cooling load from the condenser of heat pump unit. Two groups of electric heaters, each with power of $11 \mathrm{~kW}$ were located in the tank to heat the water. In order to prevent heat loss, insulation material with $25 \mathrm{~mm}$ thickness covered the outside surface of the water tank.

The ground heat exchanger: In this experimental system, three vertical GHEs with different pipe styles (shown in Figure 2) were utilized to explore the heat release characteristics of different style GHEs. One is the single U-tube GHE with $32 \mathrm{~mm}$ outside diameter and $26 \mathrm{~mm}$ inside diameter, 
the other is the double U-tube GHE with $25 \mathrm{~mm}$ outside diameter and $20 \mathrm{~mm}$ inside diameter, and the third is three pipe type with one inlet pipe of $32 \mathrm{~mm}$ outside diameter and $26 \mathrm{~mm}$ inside diameter and two outlet pipes of $25 \mathrm{~mm}$ outside diameter and $20 \mathrm{~mm}$ inside diameter. All GHEs were made using high density polyethylene (HDPE) tubes, and the borehole depths are $50 \mathrm{~m}$ for all GHEs.

Cooling tower: A circular open type wet counter flow cooling tower was utilized to assist heat release. Its cooling water amount is $15 \mathrm{t} / \mathrm{h}$ and the power of the fan is $1.5 \mathrm{~kW}$.

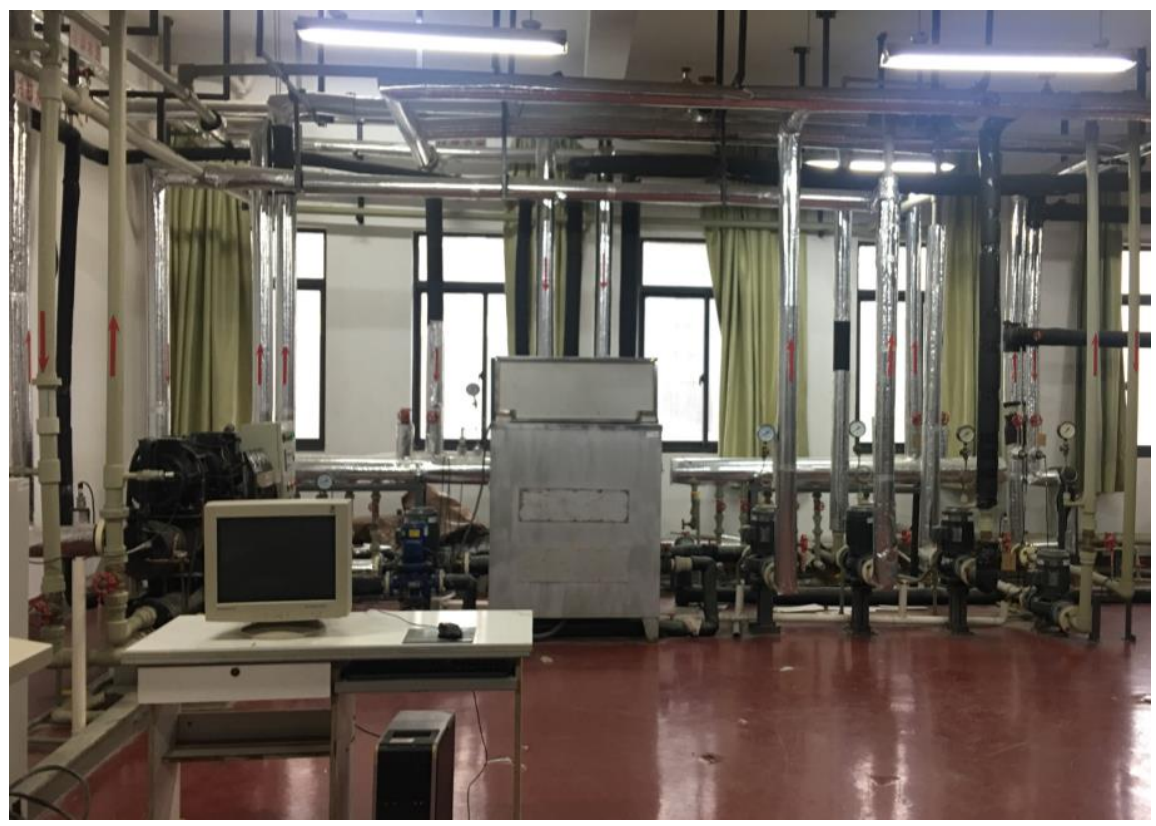

(a)

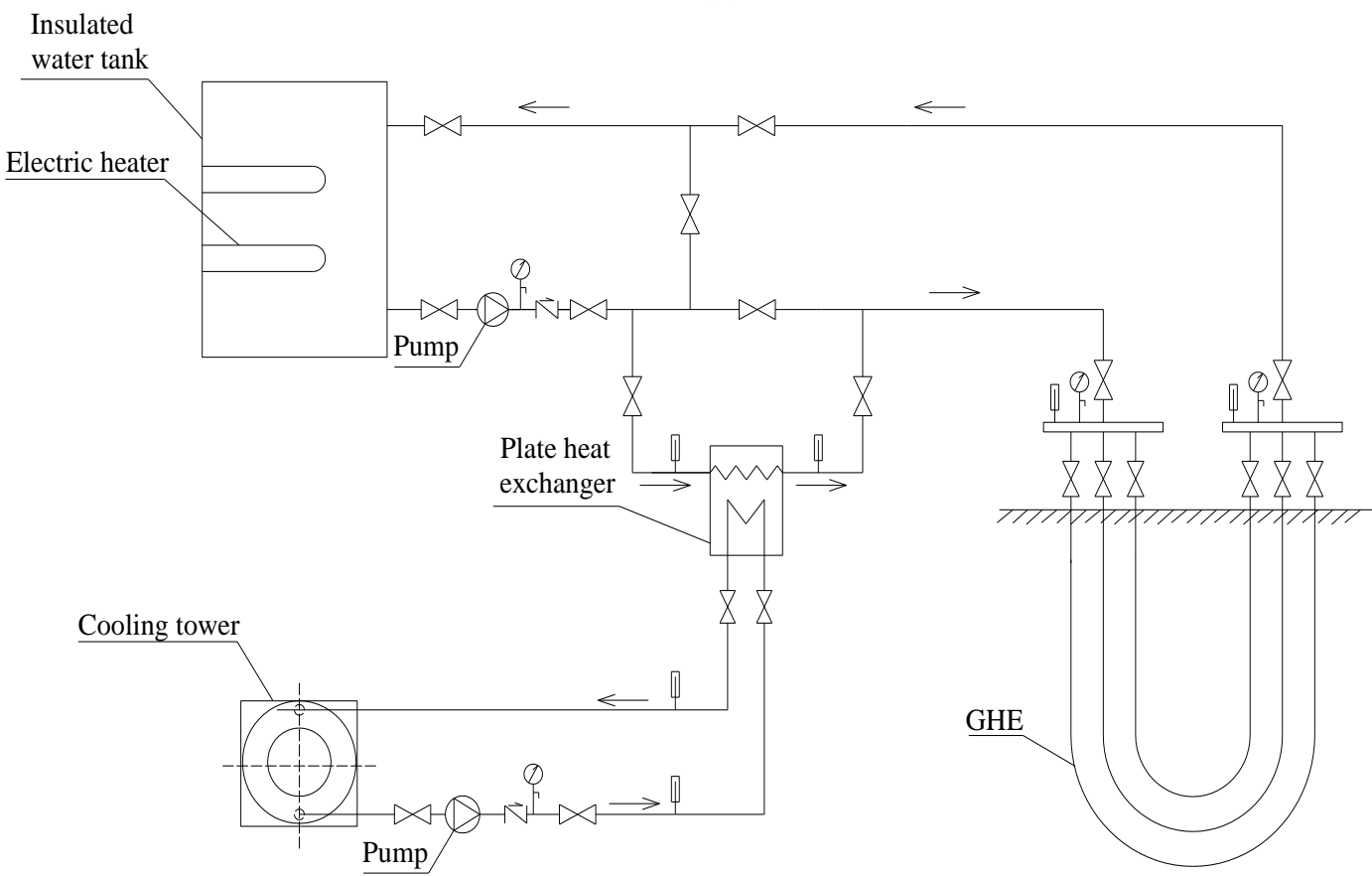

(b)

Figure 1. The experimental system built in this paper: (a) Picture of the experimental system; (b) Schematic diagram of the experimental system. 


\subsection{Measurement System}

The experimental data measurement system includes a temperature and flow rate acquisition system. The temperature measurement system consists of underground soil temperature measure and loop water temperature measuring system. For the underground soil temperature measuring system, for monitoring the temperature variations of soil at different depths, considering the cost of sensors and difficulties of data acquisition and processing, 10 PT1000 platinum resistance temperature sensors are wrapped on the outer wall of GHE with glue tape and buried in the soil at different depths with $10,15,25,35,45,52 \mathrm{~m}$ away from the top of ground surface (shown in Figure 3). All temperature measuring points are implemented automatically by the Agilent data logger connected to computer. For the loop water temperature measurement, 9 K-type thermocouples are utilized to test the entrance and exit temperatures of GHEs and cooling tower and outdoor air temperature. The TRPPIE TP700 multi-channel temperature measuring instrument is utilized here to collect these temperature test points. The flow rate measurements of GHE loop and cooling tower loop are completed through the LWGY type turbine flow meter.

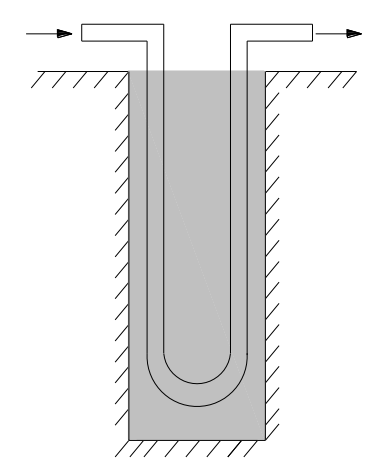

(a)

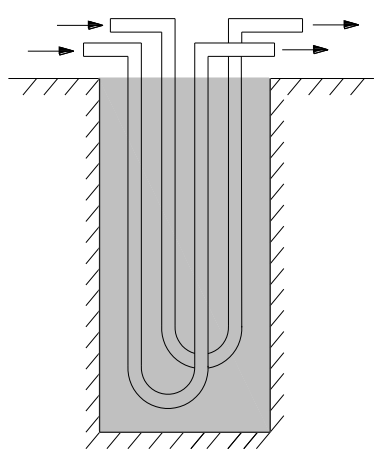

(b)

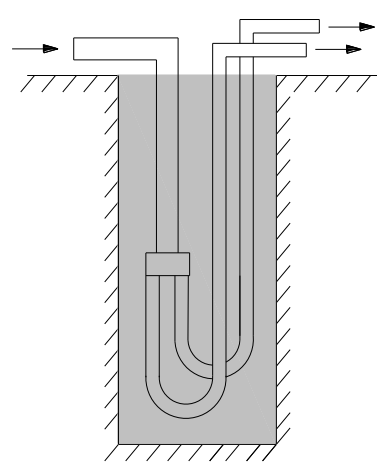

(c)

Figure 2. Vertical GHEs with three different pipe style for the experiments: (a) Single U tube GHE; (b) Double U tube GHE; (c) $1+2$ type GHE.

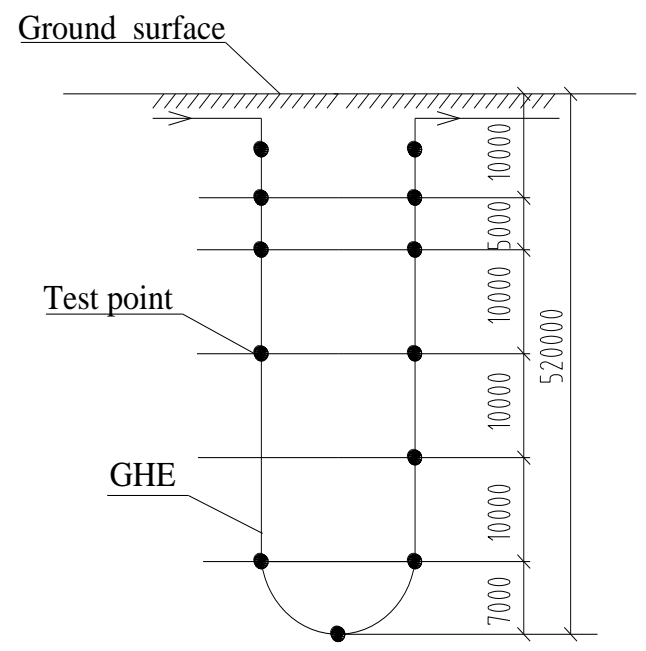

Figure 3. The layout of test points for the GHE. 


\section{Experimental Performance Analysis}

\subsection{Experimental Operation Modes}

To obtain system heat release characteristics with different coupled modes of GHE and cooling tower, the following four experimental modes were tested in this study.

\subsubsection{Separate GHE Heat Release Mode}

The separate GHE heat release mode means that it only utilizes the GHE as heat reject apparatus to remove the waste heat from the condenser of the heat pump unit. It can be used as a comparison reference for the combination and alternate heat release modes presented below.

\subsubsection{Combination Heat Release Mode}

The combination heat release mode refers to the operation state where the cooling tower and GHE are used as heat rejection apparatus synchronously through the plate heat exchanger during the daytime. In accordance with the continuity of cooling tower operation, the heat release mode can be subdivided into the following two modes:

- Mode 1: During daytime, the GHE is used continuously for rejecting heat into the soil and the cooling tower is operated continuously to reject heat into air. At night, the system is off. The mode is fit in the case of a large continuous cooling load in summer, and it can reduce the amount of heat released into the soil by the GHE, which is beneficial to the natural restoration of soil temperature.

- Mode 2: During daytime, the GHE is used continuously for rejecting heat into the soil and the cooling tower is operated intermittently to reject heat into air. At night, the system is off. The mode is fit in the case of intermittent cooling load in summer, and the heat release amount can be shared by the intermittent opening of the cooling tower.

\subsubsection{Day and Night Alternate Heat Release Mode}

The day and night alternate heat release mode is defined as an operation state where the waste heat from the condenser of the heat pump unit is released into the soil by the GHE during the daytime, and then the part of heat stored in the soil is rejected to air by operating the cooling tower during the night. The mode can accelerate soil temperature recovery by utilizing the lower outdoor air temperature at night, which is beneficial to the operation of GSHP during the second day.

\subsection{Experimental Data Processing}

The heat release rate by the GHE and cooling tower, heat release ratio by the cooling tower, soil excess temperature and soil temperature recovery rate were calculated based on the experimental data obtained in this experiment.

Heat release rate by the GHE can be determined as follows:

$$
Q_{g}=c_{p} \dot{m}_{g}\left(T_{g, \text { in }}-T_{g, o u t}\right)
$$

where $Q_{g}$ is the heat release rate by the GHE, $\mathrm{kW} . c_{p}$ is the specific heat of fluid, $\mathrm{kJ} /\left(\mathrm{kg} \cdot{ }^{\circ} \mathrm{C}\right) . \dot{m}_{g}$ is the mass flow rate in the GHE, $\mathrm{kg} / \mathrm{s}$. $T_{g, \text { in }}$ and $T_{g, o u t}$ are the fluid temperature of GHE at the inlet and outlet correspondingly, ${ }^{\circ} \mathrm{C}$.

Heat release rate by the cooling tower can be calculated as follows:

$$
Q_{c t}=c_{p} \dot{m}_{c t}\left(T_{c t, i n}-T_{c t, o u t}\right)
$$

where $Q_{c t}$ is the heat release rate by the cooling tower, $\mathrm{kW} . c_{p}$ is the specific heat of fluid, $\mathrm{kJ} /\left(\mathrm{kg} \cdot{ }^{\circ} \mathrm{C}\right)$. $\dot{m}_{c t}$ is the mass flow rate through the cooling tower, $\mathrm{kg} / \mathrm{s}$. $T_{c t, i n}$ and $T_{c t, o u t}$ are the fluid temperature of cooling tower at the inlet and outlet correspondingly, ${ }^{\circ} \mathrm{C}$. 
Heat release ratio by the cooling tower can be expressed as:

$$
\eta=\frac{Q_{c t}}{Q_{\text {total }}}
$$

where $\eta$ is the heat release ratio by the cooling tower. $Q_{\text {total }}$ is the total heat release rate by the GHE and cooling tower, $\mathrm{kW}$.

The soil excess temperature, which refers to the difference between the measured temperature and initial temperature of soil, is selected here to express the soil temperature rise velocity during the heat release operation. It can be written as:

$$
\theta=T_{g}-T_{0}
$$

where $\theta$ is the soil excess temperature, ${ }^{\circ} \mathrm{C} . T_{g}$ and $T_{0}$ are the measured soil temperature and corresponding initial temperature, respectively, ${ }^{\circ} \mathrm{C}$.

The soil temperature resuming rate, which reflects the soil temperature resuming state after the heat release operation, can be calculated as:

$$
f=1-\frac{\theta}{T_{0}}
$$

where $f$ is the soil temperature resuming rate.

\subsection{Error Analysis}

In this experiment, the measured parameters include the temperatures and flow rates, and the heat release rates were calculated. Thus, the error analysis here involves error estimations for these measured and calculated parameters.

The relative error for the measured parameters $\left(\delta R x_{i}\right)$ and calculated parameters $(\delta R F)$ can be calculated as following [38]:

$$
\begin{gathered}
\delta x_{i}=A \gamma_{i} \\
\delta R x_{i}=\frac{\delta x_{i}}{x_{i}} \\
\delta R F=\frac{\sqrt{\sum_{1}^{n}\left(\frac{\partial F_{i}}{\partial x_{i}} \delta x_{i}\right)^{2}}}{F}
\end{gathered}
$$

where $A$ is the upper limit of testing range. $\gamma_{i}$ is the accuracy grade from the manufacturer. $F$ is a function of a series of measured independent variables $x_{i}$. The errors of major parameters in the experiment are listed in Table 1.

Table 1. Errors of the major parameters in the experiment.

\begin{tabular}{cccc}
\hline Parameters & Type of Data & Unit & Relative Error \\
\hline Average inlet water temperature of GHE & Measured & ${ }^{\circ} \mathrm{C}$ & $4.4 \%$ \\
Average outlet water temperature of GHE & Measured & ${ }^{\circ} \mathrm{C}$ & $4.3 \%$ \\
Average inlet water temperature of cooling tower & Measured & ${ }^{\circ} \mathrm{C}$ & $4.1 \%$ \\
Average outlet water temperature of cooling tower & Measured & ${ }^{\circ} \mathrm{C}$ & $3.9 \%$ \\
Average inlet water temperature of water tank & Measured & ${ }^{\circ} \mathrm{C}$ & $4.0 \%$ \\
Average outlet water temperature of water tank & Measured & ${ }^{\circ} \mathrm{C}$ & $4.0 \%$ \\
Average outdoor air temperature & Measured & ${ }^{\circ} \mathrm{C}$ & $4.5 \%$ \\
Average ground temperature & Measured & ${ }^{\circ} \mathrm{C}$ & $5.2 \%$ \\
Average flow rate of GHE loop & Measured & $\mathrm{m}^{3} / \mathrm{h}$ & $4.2 \%$ \\
Average flow rate of cooling tower loop & Measured & $\mathrm{m}^{3} / \mathrm{h}$ & $4.8 \%$ \\
Average heat release rate of cooling tower & Calculated & $\mathrm{W}$ & $5.1 \%$ \\
Average heat release rate of GHE & Calculated & $\mathrm{W}$ & $5.2 \%$ \\
\hline
\end{tabular}




\section{Experimental Results and Discussion}

\subsection{Separate GHE Heat Release Mode}

In order to explore the heat release operation characteristics under separate GHE heat release modes and provide a comparison base for the combination and alternate heat release modes, a continuous heat release experiment by the separate GHE has been carried out. The heat release time is from 8:00 to 16:00, and the soil temperature recovery time is from 16:00 to 8:00. The test results are shown in Figures 4-6.

It can be seen from Figure 4 that the heat release rate of GHE rises rapidly during the first two-hour operation, then gradually tends to be steady. After 12:00, the heat release operation reaches a quasi-steady state, and the corresponding average heat release rate is about $10.24 \mathrm{~kW}$. The most probable reason is that during the start-up stage of heat release, the heat release process is unstable and the water temperature in the water tank is lower, resulting in the temperature difference between the water inside the GHE and the soil being smaller, and thus, the heat release rate being smaller. However, with the duration of heat release operation the water and soil temperatures gradually increase which leads to the heat transfer temperature difference gradually becoming steady. As shown in Figure 5, the soil excess temperatures at different depths gradually increase with time during the heat release operation. For example, the soil excess temperatures at the end of an eight-hour heat release operation are $7.39,7.32$ and $6.74{ }^{\circ} \mathrm{C}$ for the depth of 10,35 , and $52 \mathrm{~m}$, respectively. Obviously, the soil excess temperature decreases as the depth increases. Further analysis on Figure 6 can show that after 16:00, when the heat release operation is off, the soil temperatures at different depths gradually resume, and the resumed effects at $10 \mathrm{~m}$ depth are obviously better than the other two depths. The most likely reasons are that there are different ground physical properties or the cooling effect of underground water streams vary with depth, which results in that the heat release rate and temperature diffusion varying with depth in this zone.

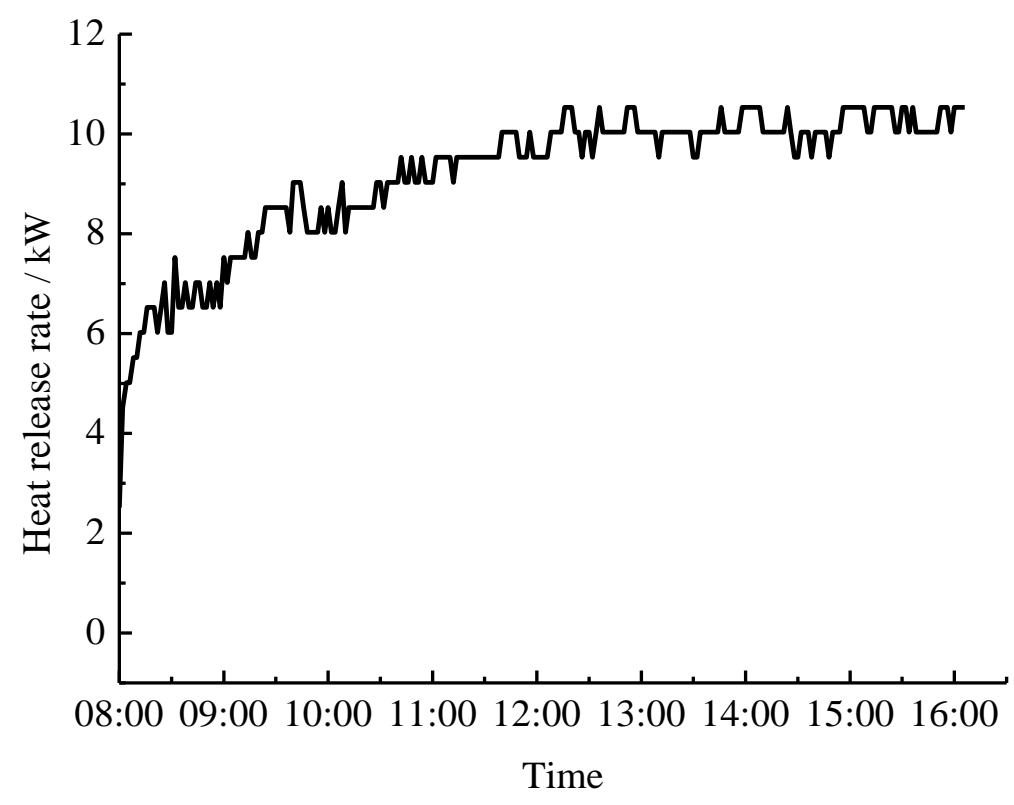

Figure 4. Variation curve of heat release rate of GHE under separate GHE heat release mode with time. 


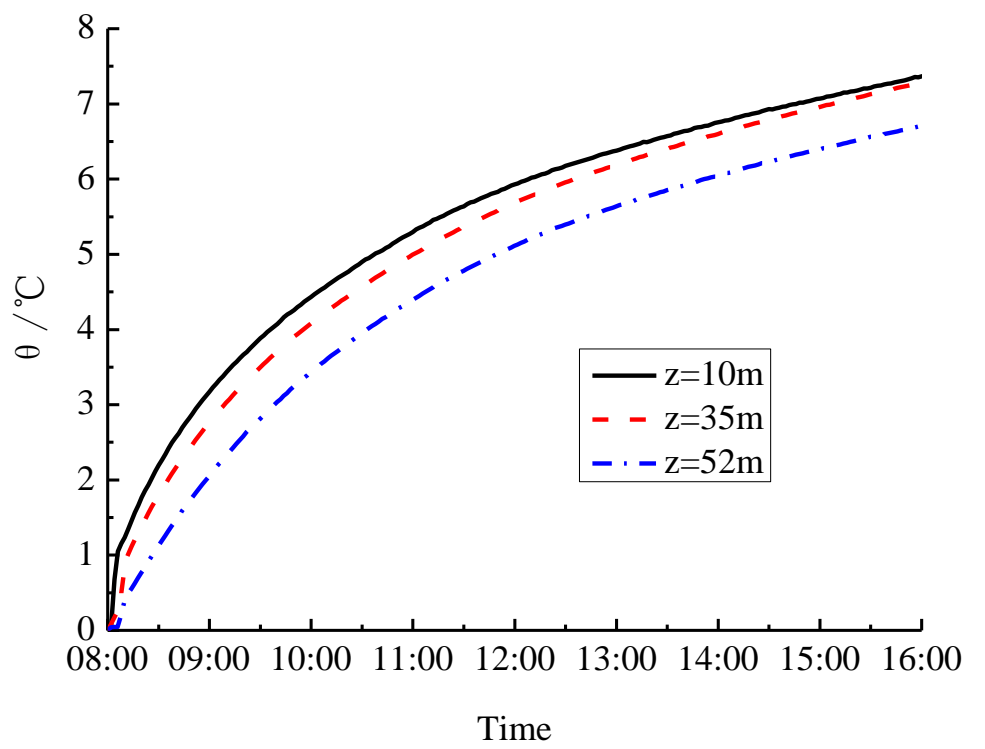

Figure 5. Variation curves of soil excess temperature with time for different depths.

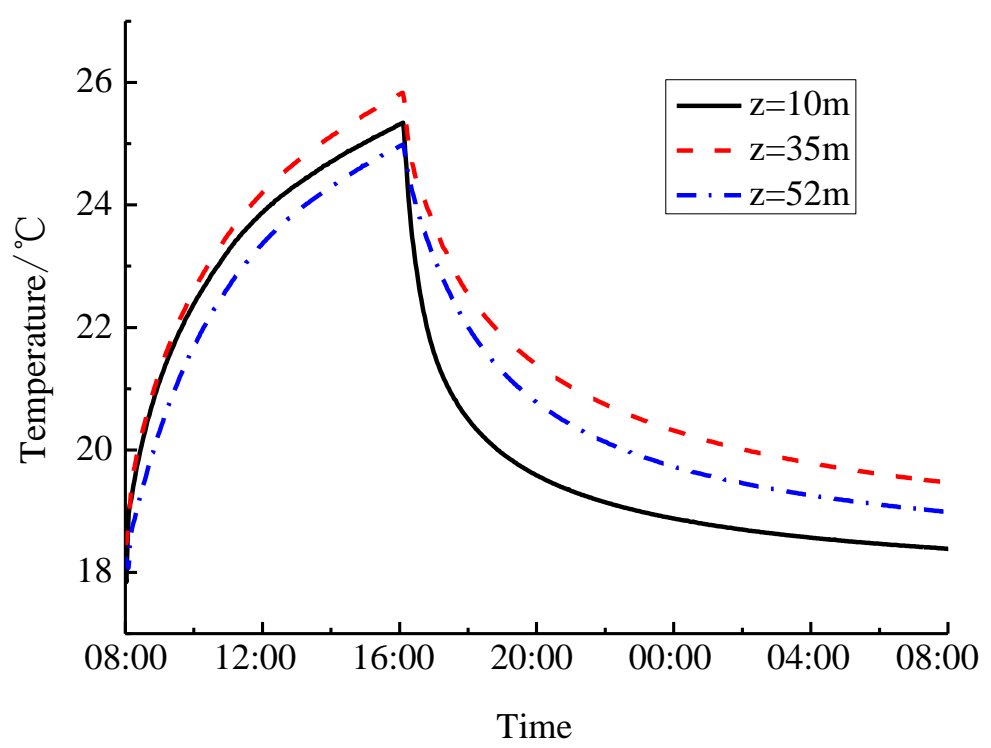

Figure 6. Variation curves of soil temperature with time for different depths.

\subsection{Combination Heat Release Mode}

\subsubsection{Mode 1}

As stated above, when the heat is released into the soil by the separate GHE, the soil temperature will increase continuously. This would be bad for the second day's running of GSHP. In order to accelerate the soil temperature recovery, the combination heat release mode, which uses the GHE and cooling tower to reject heat into the soil and air, respectively, was put forward and tested here. To further investigate the influence of weather conditions on the combination heat release operation characteristics, the experimental studies under sunny and rainy days were carried out for the heat release mode. Table 2 lists the meteorological parameters for these two kinds of weather conditions, and the experimental results are presented in Figures 7 and 8, and Table 3. 
Table 2. Meteorological parameters for two kinds of weather conditions.

\begin{tabular}{cccc}
\hline Weather & Dry Bulb Temperature $/{ }^{\circ} \mathbf{C}$ & Average Wet Bulb Temperature $/{ }^{\circ} \mathbf{C}$ & Wind Force \\
\hline Sunny day & $18-23$ & 20.5 & $4-5$ Class \\
Rainy day & $12-25$ & 23.6 & $<3$ Class \\
\hline
\end{tabular}

Table 3. The average heat release rate by the GHE and cooling tower during the test period for two kinds of weather conditions.

\begin{tabular}{cccc}
\hline Weather & $\begin{array}{c}\text { Average Heat Release Rate } \\
\text { of GHE/kW }\end{array}$ & $\begin{array}{c}\text { Average Heat Release Rate by } \\
\text { Cooling Tower/kW }\end{array}$ & $\begin{array}{c}\text { Heat Release Ratio by } \\
\text { Cooling Tower/\% }\end{array}$ \\
\hline Sunny day & 6.5 & 4.3 & 40 \\
Rainy day & 7.17 & 3.18 & 30.7 \\
\hline
\end{tabular}

From Figure 7, we can find that the variation laws of heat release rate of GHE with time are basically the same for two weather conditions, which drops rapidly in the early stage of heat release operation, then the drop degree becomes small and gradually tends to be a dynamic equilibrium. But the variation of heat release rate by the cooling tower with time has totally different laws. As shown in Figure 7, for the sunny day, the heat release rate by the cooling tower gradually becomes small with time and reaches the minimum value at about 12:00, and then begins to increase with time. The most possible reason is that the outdoor air temperature is lower in the morning and afternoon than at noon, which results in a larger heat transfer temperature difference between the cooling water and outdoor air, and as a result a larger heat release rate. But for the rainy day, the heat release rate by the cooling tower is gradually decreasing with time and tends to be a stable value after 13:00. Obviously, the heat release rate by the cooling tower under the rainy day is larger in the morning and smaller in the afternoon than under the sunny day. The main reason for this variation law is that the outdoor air temperature is lower in the morning for the rainy day, and at the same time the air relative humidity is also small. This results in a larger heat release rate by the cooling tower. But as the rain continues, the air is gradually humidified and accordingly the air wet bulb temperature increases, which leads to the decrease of heat release rate of cooling tower by the evaporative cooling mode, and thus, the total heat release rate drops. Further analysis of Figure 8 shows that the soil excess temperature at $10 \mathrm{~m}$ depth under the rainy day is obviously higher than that under the sunny day. For example, after eight hours of operation, the soil excess temperature is $5.3^{\circ} \mathrm{C}$ for a rainy day, and the corresponding value is $4.4^{\circ} \mathrm{C}$ for a sunny day. This is caused mostly by the fact that the heat released into the soil under the rainy day is larger than the sunny day, which results in a larger soil temperature rise. As shown in Table 3, the heat release rate by the GHE and the heat release ratio by the cooling tower are $6.5 \mathrm{~kW}$, $40 \%$ and $7.17 \mathrm{~kW}, 30.7 \%$ for sunny day and rainy day, respectively. Obviously, the ratio of heat release by the cooling tower for the sunny day is about $10 \%$ larger than rainy day. This means that under the same conditions, the sunny day is more conducive to the heat release by the cooling tower. Therefore, from the point of view of reducing soil heat accumulation and accelerating soil temperature recovery, it is more favorable for soil temperature recovery to open the cooling tower on sunny days. 


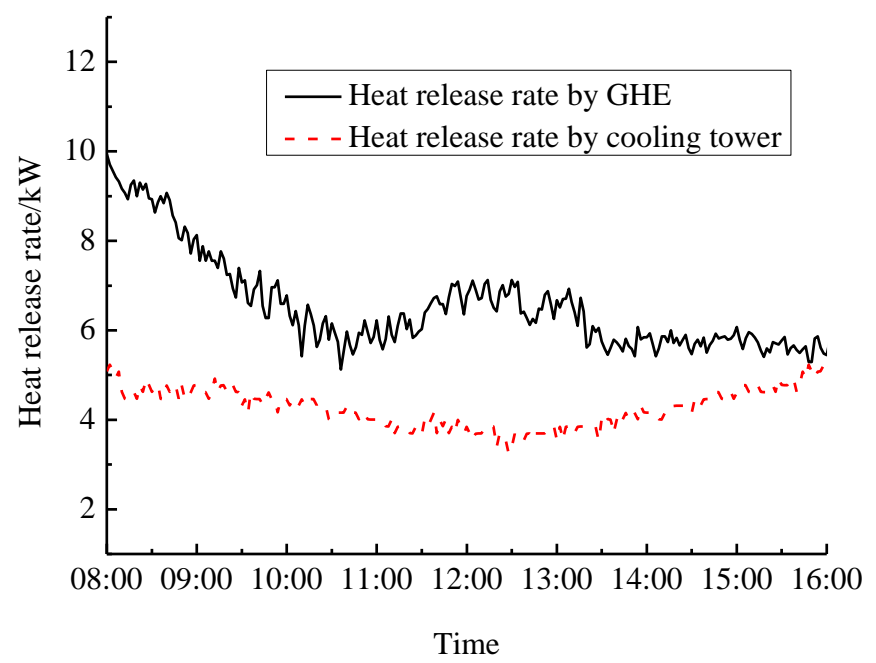

(a)

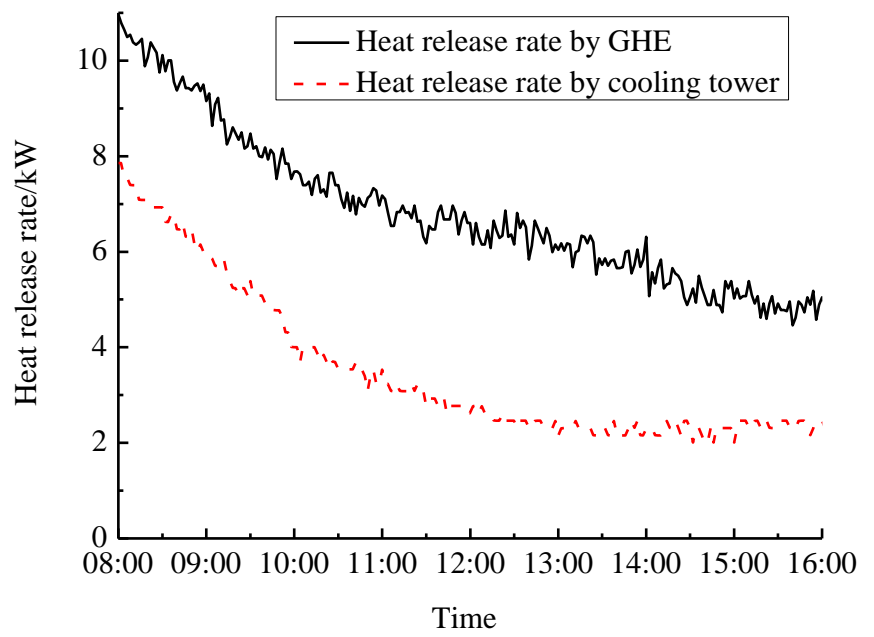

(b)

Figure 7. Variation curves of heat release rate by GHE and cooling tower with time for the continuous operation mode of cooling tower: (a) Sunny day; (b) Rainy day.

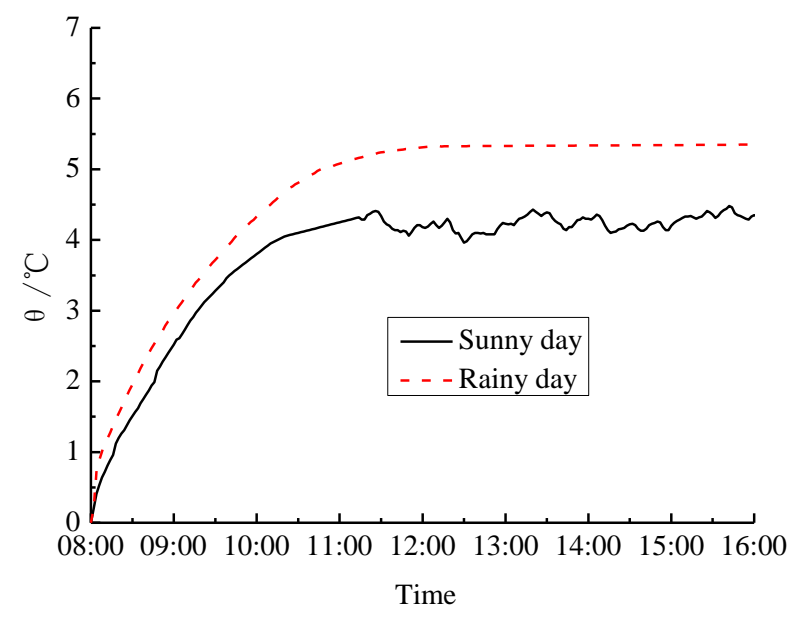

Figure 8. Variation curves of soil excess temperature at $10 \mathrm{~m}$ depth under different weather conditions with time for the continuous operation mode of cooling tower. 


\subsubsection{Mode 2}

In order to further explore the effects of intermittent operation of cooling tower on the heat release performance and soil temperature recovery characteristics, the intermittent operation modes of cooling tower with one hour on and one hour off and two hours on and two hours off were tested in this work. The heat release operation time is from 8:00 to 16:00 and the soil temperature recovery time is from 16:00 to 8:00. The experimental results are shown in Figures 9 and 10.

Figure 9 shows that for two kinds of intermittent modes, the heat release rates by the GHE all gradually decrease with time, and have a sudden drop when the cooling tower is started. As shown in Figure 9a, the heat release rate of GHE suddenly drops from $7.2 \mathrm{~kW}$ to $4.1 \mathrm{~kW}$ at 10:00 when the cooling tower is started for the intermittent operation modes of cooling tower with one hour on and one hour off. This can also been found in Figure $9 \mathrm{~b}$ where the heat release rate of GHE suddenly drops from $6.5 \mathrm{~kW}$ to $1.8 \mathrm{~kW}$ at 12:00 for the intermittent operation modes of cooling tower with two hours on and two hours off. The most possible reason is that the part of heat release has been rejected into air when the cooling tower is started. It can be further seen from Figure 10 that the soil excess temperature at $35 \mathrm{~m}$ depth under the intermittent mode of one hour on and one hour off is higher than two hours on and two hours off. For example, the soil excess temperatures at the end of operation time are 6.5 and $6{ }^{\circ} \mathrm{C}$ for the intermittent modes of one hour on and one hour off and two hours on and two hours off, respectively. The most possible reason is that a large intermittent time is beneficial to the soil thermal diffusivity and, at the same time, more heat can be rejected into the air by the cooling tower. This means that when the total time ratio of cooling tower operation to stop is constant, the longer the intermittent time, the better the soil temperature restoration effect.

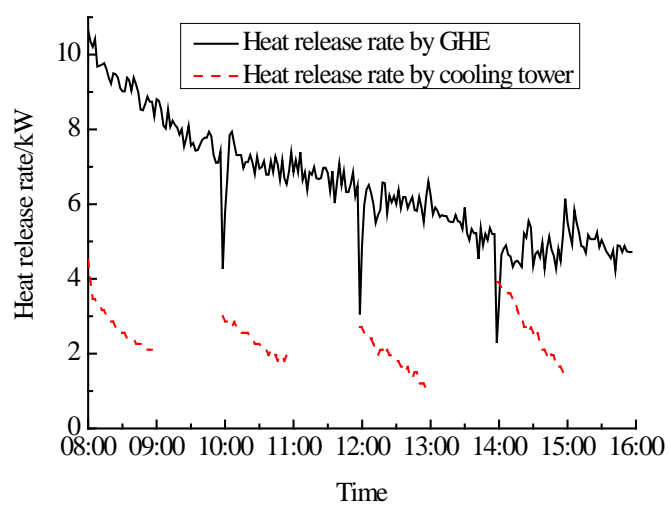

(a)

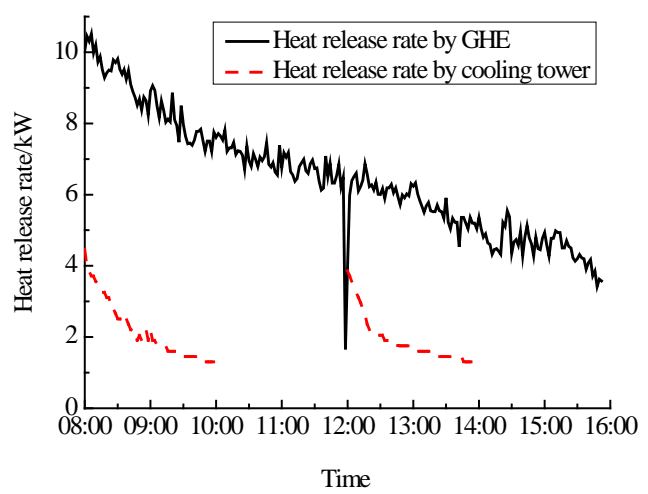

(b)

Figure 9. Variation curves of heat release rate by the GHE and cooling tower with time for two intermittent operation modes of cooling tower: (a) one hour on and one hour off; (b)two hours on and two hours off. 


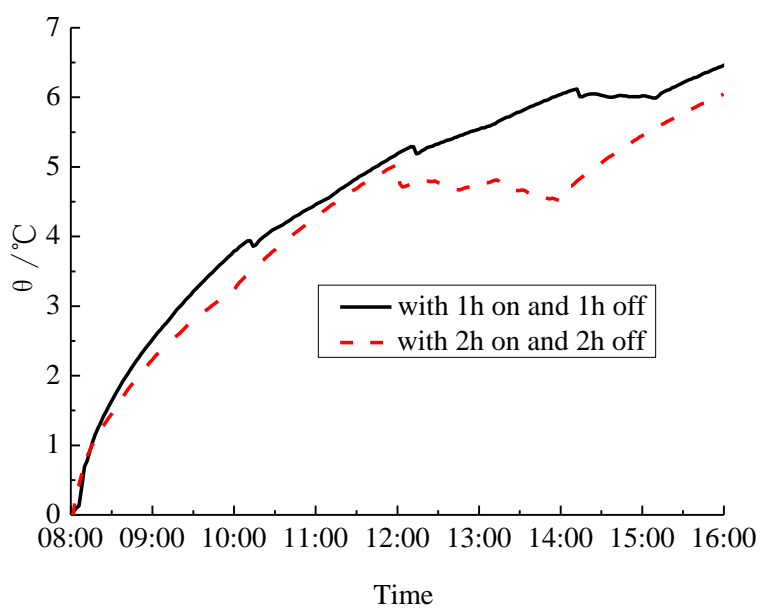

Figure 10. Variation curves of soil excess temperature at $35 \mathrm{~m}$ depth under two intermittent modes with time for the intermittent operation mode of cooling tower.

\subsection{Day and Night Alternate Heat Release Mode}

In order to investigate the effects of the day and night alternate heat release mode on the soil temperature resuming rate, the soil temperature natural resuming mode, three-hour and six-hour release heat modes by the cooling tower were respectively carried out in this experiment. The experimental results are shown in Figure 11.

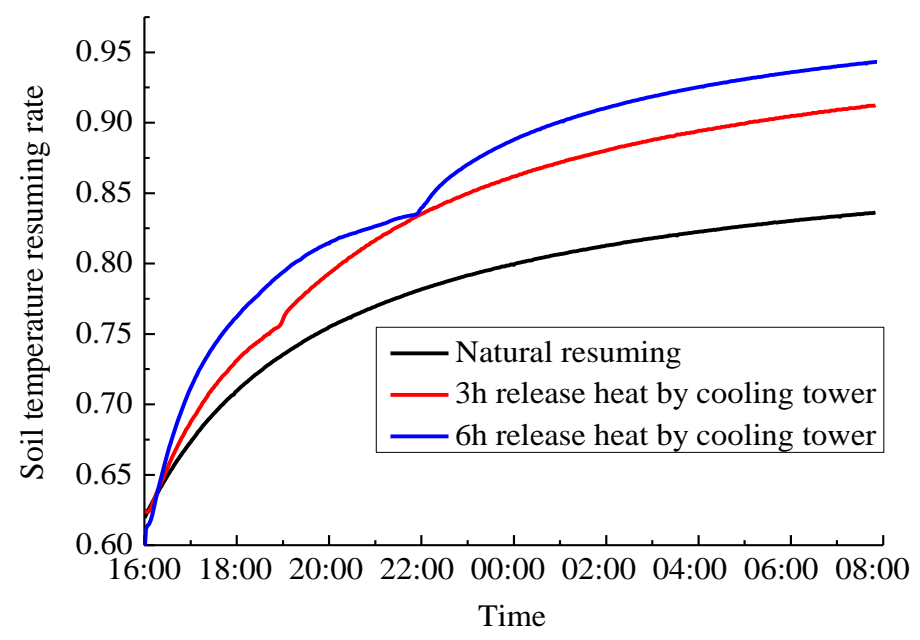

Figure 11. Variation curves of soil temperature resuming rate with time for the day and night alternate heat release mode with different cooling tower operation time.

It can be seen from Figure 11 that for the soil temperature natural resuming mode, the soil temperature resuming rate is 0.84 after the natural resuming of 16 hours during the night. But for the day and night alternate heat release mode with different cooling tower operation times, the soil temperature resuming rate can reach 0.91 and 0.94 for the three hours and six hours of operation of cooling tower at night, respectively. Obviously, the soil recovery rates of the latter two are higher than those of the former. Thus, the night cooling tower assisted release heat operation can effectively improve the recovery rate of soil temperature, and the longer the operation time, the closer the soil temperature is to the initial temperature. 


\section{Conclusions}

In order to investigate the effects of different heat release operation modes of cooling tower on the heat release rate of GHE and soil temperature variation characteristics, experimental studies on the heat release operation characteristics of soil coupled ground heat exchanger with assisted cooling tower were carried out. The separate GHE heat release mode, the combination heat release mode and the day and night alternate heat release mode were tested here. The following conclusions can be obtained.

(1) For the GHE separate heat release mode, the heat release rate of GHE rises rapidly during the first two hours of operation, and then gradually tends to be steady. The soil excess temperatures at different depths gradually increase with time during the heat release operation. And the soil excess temperature decreases as the depth increases.

(2) For the combination heat release mode with continuous operation of cooling tower, under the same conditions, it is more conducive to heat release by opening the cooling tower on sunny days, which can reduce soil heat accumulation and accelerate soil temperature recovery. The heat release rate by the GHE and the heat release ratio by the cooling tower are $6.5 \mathrm{~kW}, 40 \%$ and $7.17 \mathrm{~kW}, 30.7 \%$ for sunny day and rainy day, respectively.

(3) For the combination heat release mode with intermittent operation of cooling tower, when the total time ratio of cooling tower operation to stop is constant, the longer the intermittent time, the better the soil temperature restoration effect. For this experiment, the soil excess temperatures at the end of operation time are 6.5 and $6{ }^{\circ} \mathrm{C}$ for the intermittent modes of one hour on and one hour off and two hours on and two hours off, respectively.

(4) The night cooling tower assisted release heat operation can effectively improve the recovery rate of soil temperature, and the longer the operation time, the closer the soil temperature is to the initial temperature. For the experimental conditions here, the soil temperature recovery rate are 0.84, 0.91 and 0.94 for the natural resuming mode, cooling tower assisted release heat mode with three hours and six hours of operation, respectively.

Acknowledgments: The work is supported by the State Key Laboratory for Geo Mechanics and Deep Underground Engineering, China University of Mining \& Technology No.SKLGDUEK1711, Yangzhou Science and Technology Project No.YZ2016248, Foundation of Key Laboratory of Efficient \& Clean Energy Utilization, The Education Department of Hunan Province No.2016NGQ002, Foundation of Key Laboratory of Thermo-Fluid Science and Engineering (Xi'an Jiaotong University), Ministry of Education No. KLTFSE2016KF05, Foundation of Guang Xi Key Laboratory of New Energy and Building Energy saving-Guilin University of Technology No.15-J-22-3.

Author Contributions: All authors contributed in the preparation of this manuscript. Weibo Yang implemented the main research, checked, and discussed the results. Binbin Yang and Rui Xu checked the writing.

Conflicts of Interest: The authors declare no conflict of interest.

\section{References}

1. Yuan, Y.P.; Cao, X.L.; Sun, L.L.; Lei, B.; Yu, N.Y. Ground source heat pump system: A review of simulation in china. Renew. Sustain. Energy Rev. 2012, 16, 6814-6822. [CrossRef]

2. Yuan, Y.P.; Cao, X.L.; Wang, J.Q.; Sun, L.L. Thermal interaction of multiple ground heat exchangers under different intermittent ratio and separation distance. Appl. Therm. Eng. 2016, 108, 277-286. [CrossRef]

3. Beier, R.A. Transient heat transfer in a u-tube borehole heat exchanger. Appl. Therm. Eng. 2014, 62, $256-266$. [CrossRef]

4. Yang, W.B.; Chen, Y.P.; Shi, M.H.; Spitler, J.D. Numerical investigation on the underground thermal imbalance of ground-coupled heat pump operated in cooling-dominated district. Appl. Therm. Eng. 2013, 58, 626-637. [CrossRef]

5. Kavanaugh, S.P. A design method for hybrid ground-source heat pumps. ASHRAE Trans. 1998, 104, 691-698.

6. Yavuzturk, C.; Spitler, J.D. Comparative study of operating and control strategies for hybrid ground source heat pump systems using a short time step simulation model. ASHRAE Trans. 2000, 106, 192-209. 
7. Lee, J.S.; Song, K.S.; Ahn, J.H.; Kim, Y.C. Comparison on the transient cooling performances of hybrid ground source heat pumps with various flow loop configurations. Energy 2015, 82, 678-685. [CrossRef]

8. Balasubramanian, S.; Gaspredes, J.L.; Moon, T.J.; Masada, G.Y. Feasibility study of a residential hybrid groundsource heat pump system. J. Therm. Sci. Eng. Appl. 2016, 3, 512-524.

9. Sayyadi, H.; Nejatolahi, M. Thermodynamic and thermoeconomic optimization of a cooling tower-assisted ground source heat pump. Geothermics 2011, 40, 221-232. [CrossRef]

10. Man, Y.; Yang, H.X.; Fang, Z.H. Study on hybrid ground-coupled heat pump systems. Energy Build. 2008, 40, 2028-2036.

11. Man, Y.; Yang, H.X.; Wang, J.G. Study on hybrid ground-coupled heat pump system for air-conditioning in hot-weather areas like Hong Kong. Appl. Energy 2010, 87, 2826-2833. [CrossRef]

12. Cui, W.Z.; Zhou, S.Y.; Liu, X.Y. Optimization of design and operation parameters for hybrid ground-source heat pump assisted with cooling tower. Energy Build. 2015, 99, 253-262. [CrossRef]

13. Chiasson, A.D.; Yavuzturk, C.C.; Johnson, D.W.; Filburn, T.P. Optimization of the ground thermal response in hybrid geothermal heat pump systems. ASHRAE Trans. 2010, 116, 512-524.

14. Gang, W.J.; Wang, J.B.; Wang, S.W. Performance analysis of hybrid ground source heat pump systems based on ANN predictive control. Appl. Energy. 2014, 136, 1138-1144. [CrossRef]

15. Singh, K.; Das, R. Exergy optimization of cooling tower for HGSHP and HVAC applications. Energy Convers. Manag. 2017, 136, 418-430. [CrossRef]

16. Yang, J.; Xu, L.H.; Hu, P.F.; Zhu, N.; Chen, X.P. Study on intermittent operation strategies of a hybrid ground-source heat pump system with double-cooling towers for hotel building. Energy Build. 2014, 76, 506-512. [CrossRef]

17. Zhang, Q.; Lv, N.; Chen, S.P.; Shi, H.; Chen, Z.Q. Study on operating and control strategies for hybrid ground source heat pump system. Procedia Eng. 2015, 121, 1894-1901. [CrossRef]

18. Sagia, Z.; Rakopoulos, C. New control strategy for a hybrid ground source heat pump system coupled to a closed circuit cooling tower. J. Appl. Mech. Eng. 2012, 1, 1146-1153. [CrossRef]

19. Lubis, L.I.; Kanoglu, M.; Dincer, I.; Shi, H.; Chen, Z.Q. Thermodynamic analysis of a hybrid geothermal heat pump system. Geothermics 2011, 40, 233-238. [CrossRef]

20. Lee, J.S.; Park, H.; Kim, Y. Transient performance characteristics of a hybrid ground-source heat pump in the cooling mode. Appl. Energy 2014, 123, 121-128. [CrossRef]

21. Zhou, S.Y.; Cui, W.Z.; Li, Z.S.; Liu, X.Y. Feasibility study on two schemes for alleviating the underground heat accumulation of the ground source heat pump. Sustain. Cities Soc. 2016, 24, 1-9. [CrossRef]

22. Wei, X.Q.; Li, N.P.; Peng, J.Q.; Cheng, J.L.; Hu, J.H.; Wang, M. Modeling and optimization of a cooling tower-assisted heat pump system. Energies 2017, 10, 733. [CrossRef]

23. Gang, W.J.; Wang, J.B. Predictive ANN models of ground heat exchanger for the control of hybrid ground source heat pump systems. Appl. Energy 2013, 112, 1146-1153. [CrossRef]

24. Sagia, Z.; Rakopoulos, C.; Kakaras, E. Cooling dominated hybrid ground source heat pump system application. Appl. Energy 2012, 94, 41-47. [CrossRef]

25. Wang, L.Y.; Zhang, J.L.; Min, H.; Xu, L.H. Optimal control of cooling tower in hybrid ground-source heat pump system for hotel buildings. In Proceedings of the International Conference on Advanced Design and Manufacturing Engineering, Taiyuan, China, 24-26 August 2015; pp. 1749-1756.

26. Wang, S.J.; Liu, X.B.; Gates, S. Comparative study of control strategies for hybrid GSHP system in the cooling dominated climate. Energy Build. 2015, 89, 222-230. [CrossRef]

27. Hu, B.; Li, Y.Y.; Mu, B.J.; Wang, S.J.; Seem, J.E.; Cao, F. Extremum seeking control for efficient operation of hybrid ground source heat pump system. Renew. Energy 2016, 86, 332-346. [CrossRef]

28. Balasubramanian, S.; Gaspredes, J.; Moon, T.J.; Masada, G.Y. Cooling towers as supplemental heat rejection systems in ground source heat pumps for residential houses in Texas and other semi-arid regions. In Proceedings of the ASME International Conference on Energy Sustainability Collocated with the ASME International Conference on Fuel Cell Science, San Diego, CA, USA, 23-26 July 2012; pp. 719-729.

29. Han, Z.W.; Ju, X.M.; Ma, X.; Zhang, Y.H.; Lin, M. Simulation of the performance of a hybrid ground-coupled heat pump system on the basis of wet bulb temperature control. Appl. Therm. Eng. 2016, 108, 980-988. [CrossRef] 
30. Nguyen, H.V.; Law, Y.L.E.; Alavy, M.; Walsh, P.R.; Leong, W.H.; Dworkin, S.B. An analysis of the factors affecting hybrid ground-source heat pump installation potential in North America. Appl. Energy 2014, 125, 28-38. [CrossRef]

31. Hackel, S.; Pertzborn, A. Effective design and operation of hybrid ground-source heat pumps: Three case studies. Energy Build. 2011, 43, 3497-3504. [CrossRef]

32. Fan, R.; Gao, Y.; Hua, L.; Deng, X.X.; Shi, J. Thermal performance and operation strategy optimization for a practical hybrid ground-source heat-pump system. Energy Build. 2014, 78, 238-247. [CrossRef]

33. Park, H.; Lee, J.S.; Kim, W.; Kim, Y. Performance optimization of a hybrid ground source heat pump with the parallel configuration of a ground heat exchanger and a supplemental heat rejecter in the cooling mode. Int. J. Refrig. 2012, 35, 1537-1546. [CrossRef]

34. Wang, J.G.; Gao, X.X.; Yin, Z.J.; Fang, L. Study of operating control strategies for hybrid ground source heat pump system with supplemental cooling tower. In Proceedings of the IITA International Conference on Services Science, Zhangjiajie, China, 11-12 July 2009; pp. 507-510.

35. Park, H.; Lee, J.S.; Kim, W.; Kim, Y. The cooling seasonal performance factor of a hybrid ground-source heat pump with parallel and serial configurations. Appl. Energy 2013, 102, 877-884. [CrossRef]

36. Guo, M.; Diao, N.; Man, Y.; Fang, Z.H. Research and development of the hybrid ground-coupled heat pump technology in China. Renew. Energy 2016, 87, 1033-1044. [CrossRef]

37. Chen, D.J. Research on Operational Characteristics of Hybrid Ground Source Heat Pump with the Auxiliary Cooling Tower. Master's Thesis, Yangzhou University, Yangzhou, China, 2015.

38. Moffat, R.J. Describing the uncertainties in experimental results. Exp. Therm. Fluid Sci. 1988, 1, 3-17. [CrossRef]

(C) 2018 by the authors. Licensee MDPI, Basel, Switzerland. This article is an open access article distributed under the terms and conditions of the Creative Commons Attribution (CC BY) license (http:/ / creativecommons.org/licenses/by/4.0/). 